\title{
Strategi Dakwah Program "Bincang Ringan Angkringan” di Yufid TV
}

\author{
Ilham Cahyo Kumolo \\ Program Studi Komunikasi dan Penyiaran Islam, Universitas Muhammadiyah Yogyakarta, Indonesia \\ mastehams@gmail.com \\ Diserahkan: 9 November 2020; Direvisi: 31 Maret 2021; Diterima: 31 Maret 2021
}

\begin{abstract}
The background of this research is the fact that the knowledge about cultural da'wah (Islamic missionary endeavor) is very important for a preacher or a da'wah institution to improve the quality of the delivery of the da'wah messages to be easily accepted by the community. Moreover, it cannot be taken for granted and requires a well-organized strategy. Research on the strategy of da'wah cultural program "Bincang Ringan Angkringan" on Yufid to discusses how the cultural da'wah strategies are applied by Yufid TV in the TV program. This study used a descriptive method with a qualitative approach. The purpose of this study was to describe the strategy of cultural da'wah through social media which is presented in the "Bincang Ringan Angkringan" program on Yufid TV. Yufid TV in this program predominantly uses sensory da'wah strategies, followed by sentimental strategies, and very rarely uses rational strategies. The videos as broadcasted in the program include cultural da'wah characteristics which cover accommodation of local wisdom, the universality of Islam, rahmatan lil'alamin, and the convenience of Islam.
\end{abstract}

Keywords: Angkringan, Cultural Da'wah, Da'wah Strategy, Tufid TV.

\begin{abstract}
Abstrak
Latar belakang dari penelitian ini adalah karena pengetahuan tentang dakwah kultural menjadi sangat penting bagi seorang da'i ataupun lembaga dakwah untuk meningkatkan kualitas penyampaian pesan dakwah agar mudah diterima oleh masyarakat. Menyampaikan pesan dakwah tidak bisa dilakukan secara asal-asalan, tetapi memerlukan strategi yang tertata dengan baik. Penelitian Strategi Dakwah Kultural Dalam Program "Bincang Ringan Angkringan" di Yufid TV membahas tentang bagaimana strategi dakwah kultural yang diterapkan Yufid TV dalam program "Bincang Ringan Angkringan". Penelitian ini menggunakan metode deskriptif dengan pendekatan kualitatif. Tujuan dari penelitian ini adalah untuk mendeskripsi strategi dakwah kultural melalui media sosial yang dipresentasikan dalam program "Bincang Ringan Angkringan" di Yufid TV. Bahwasanya Yufid dalam program ini dominan menggunakan strategi dakwah indrawi, kemudian strategi sentimentil, dan sangat jarang menggunakan strategi rasional. Kemudian dalam video dakwah program Bincang Ringan Angkringan, Yufid memasukkan watak-watak dakwah kultural yang meliputi akomodasi kearifan lokal, keuniversalan Islam, rahmatan lil'alamin, dan kemudahan Islam.
\end{abstract}

Kata kunci: Angkringan, Dakwah Kultural, Strategi Dakwah, Yufid TV. 


\section{PENDAHULUAN}

Dalam menjalankan kegiatan dakwah, salah satu strateginya adalah memperhatikan keadaan medan dakwah yang akan dihadapi. Salah satu bagian dari medan dakwah adalah mitra dakwah atau sering dikenal dengan istilah mad'u. Ketika mad'u menjadi titik berat fokus subyek dakwah maka perlu pendekatan dakwah kultural. Bachtiar menyampaikan bahwa dakwah dengan pendekatan kultural, disebut sebagai pendekatan bottom-up, yaitu aktivitas dakwah yang berupaya merubah tatanan sikap, tingkah laku, dan pendapat mad'ū dengan membangun kesadaran masyarakat atau individu. Istilah ini dikenal sebagai dakwah fardhiyyah, yaitu pendekatan personal (Bachtiar, 2013).

Dalam dunia dakwah, dengan adanya perkembangan media komunikasi menjadi sarana yang sangat bermanfaat. Melalui media-media ini, dakwah Islam dapat tersiarkan ke seluruh pelosok negeri. Terutama melalui media yang berbasis audiovisual, misalnya televisi ataupun media sosial. Apalagi saat ini pengguna media sosial sudah sangatlah banyak.

Berdasarkan data yang penulis peroleh dari greenhouse.co tahun 2019 masyarakat Indonesia yang menggunakan media sosial mencapai 150 juta orang. Dengan kata lain lebih dari 50 persen penduduk Indonesia adalah pengguna media sosial. Tidak sekadar banyak pengguna media sosial, akan tetapi warganet Indonesia juga merupakan pengguna media sosial yang aktif. Rata-rata orang Indonesia menggunakan waktu mereka untuk bermedia sosial sekitar 3 jam 26 menit per hari. Sementara ratarata pengguna media sosial di dunia adalah 2 jam 22 menit (Greenhouse.co, 2019). Hal ini berarti jumlah rata-rata pengguna di Indonesia lebih lama. Data yang penulis dapat dari portal tersebut dipaparkan bahwa aplikasi media sosial youtube menduduki peringkat pertama disusul kemudian whatsaap, facebook dan instagram. Oleh karenanya media social juga bisa menjadi celah bagi $d a^{\prime} i$ ataupun lembaga dakwah untuk menyebarkan ajaran agama Islam secara lebih luas di Indonesia.

Saat ini, banyak akun-akun media sosial baik milik pribadi seorang $d a^{\prime} i$ ataupun yang mewakili lembaga dakwah menyebarkan ajaran Islam melalui postingan-postingan mereka. Salah satunya adalah Yufid TV. Yufid TV termasuk salah satu channel dakwah yang memiliki lebih dari satu juta subscriber. Data terbaru yang penulis dapatkan di awal November tahun 2020 ini, jumlah subscriber Yufid TV sudah mencapai 2,46 juta, artinya channel ini sudah mendapatkan gold button dari youtube. Bukan sekedar channel youtube yang dikelola oleh perorangan saja, namun Yufid TV memiliki kantor dan karyawan untuk mengurusi kegiatan dakwah di media sosial. Konten program dari channel Yufid TV ini juga bervariasi seperti; ceramah singkat, tilawah Al-Qur'an, film pendek, pendidikan umum, bahasa Arab, dan ada juga konten yang dibuat secara khusus untuk anak-anak.

Peneliti memilih program "Bincang Ringan Angkringan" dalam channel youtube Yufid TV ini dibandingkan dengan program lain, untuk dijadikan bahan penelitian. Hal ini dikarenakan adanya unsur budaya lokal yang dipakai oleh Yufid TV dalam menyampaikan pesan dakwah yaitu penggunaan bahasa jawa yang mana hal tersebut tidak terdapat dalam program yang lain. Oleh karena itu penulis ingin mendeskripsi bagaimana strategi dakwah kultural dalam program Bincang Ringan Angkringan tersebut. Adapun teori yang digunakan oleh penulis adalah strategi dakwah Al-Bayanuni digabungkan dengan watak dakwah kultural.

\section{KAJIAN PUSTAKA}

Al-Bayanuni memberikan penjelasan mengenai strategi dakwah dan metode dakwah. Bahwa yang dimaksud dengan strategi dakwah adalah "Pensisteman dakwah beserta rencana-rencananya yang terstruktur" (Al-Bayanuni, 1995). Sedangkan metode dakwah adalah cara-cara yang ditempuh oleh seorang da'i di dalam dakwahnya (Al-Bayanuni, 1995). Bentuk strategi dakwah, menurut Al-Bayanuni ada 3 yaitu strategi dakwah sentimentil, strategi rasional dan strategi indrawi.

Bentuk strategi dakwah yang pertama adalah strategi sentimentil (al-manhaj al-'athifi). Strategi sentimentil adalah dakwah yang memfokuskan aspek hati dan menggerakkan perasaan dan emosi mitra dakwah/mad'u (Al-Bayanuni, 1995). Ciri khas dari dakwah sentimentil adalah pertama, gaya bahasa yang digunakan lembut dan memilih kata-kata yang menyentuh hati. Kedua, mudah diterima 
oleh mitra dakwah. Ketiga, menyelipkan sedikitnya ketegangan yang muncul dengan musuh dakwah dan keempat mudah memberikan pengaruh.

Bentuk strategi dakwah rasional (al-manhaj al-'aqli) adalah dakwah dengan beberapa metode yang memfokuskan pada aspek akal pikiran. Strategi ini mendorong mitra dakwah/mad'u untuk berpikir, merenungkan dan mengambil pelajaran. Penggunaan hukum logika, diskusi atau penampilan contoh dan bukti sejarah merupakan beberapa metode dari strategi rasional. Beberapa terminologinya antara lain: tafakkur, tadzakkur, nazhar, taammul, tadabbur dan istibshar. Tafakkur adalah menggunakan pemikiran untuk mencapainya dan memikirkannya; tadzakkur merupakan menghadirkan ilmu yang harus dipelihara setelah dilupakan; nazhar ialah mengarahkan hati untuk berkonsentrasi pada objek yang sedang diperhatikan; taammul berarti mengulang-ulang pemikiran hingga menemukan kebenaran dalam hatinya; itibar bermakna perpindahan dari pengetahuan yang sedang dipikirkan menuju pengetahuan yang lain; tadabbur adalah suatu usaha memikirkan akibat-akibat setiap masalah; istibshar ialah mengungkap sesuatu atau menyingkapnya, serta memperlihatkannya kepada pandangan hati (Nizar, 2018, p. 86). Strategi rasional memiliki beberapa ciri yaitu, pertama cenderung menggunakan kesimpulan akal atau kaidah mantiqi. Kedua, di dalamnya berpengaruh terhadap mitra dakwah. Ketiga, membantah mitra dakwah. Terakhir, berperan lebih sempit daripada strategi sentimentil.

Strategi dakwah yang terakhir adalah strategi Indrawi (al-manhaj al-hissi). Bentuk strategi dakwah indrawi adalah kata lain dari strategi eksperimen atau strategi ilmiah. Strategi ini didefinisikan sebagai sistem dakwah atau kumpulan metode dakwah yang berorientasi pada panca indera dan berpegang teguh pada hasil penelitian dan percobaan. Di antara metode ini dihimpun oleh strategi yaitu praktik keagamaan, keteladanan, dan pentas drama (Nizar, 2018). Ciri strategi dakwah indrawi adalah pertama cepat memberikan pengaruh secara ilmiyah karena menampakkan hal yang langsung bisa dirasakan oleh panca indera. Kedua, dibutuhkan penggunaannya pada banyak tempat dakwah, baik tempat yang umum seperti tabligh akbar, maupun tempat yang khusus seperti mulazamah.

\section{METODE PENELITIAN}

Penelitian ini menggunakan metode deskriptif dengan pendekatan kualitatif. Hal ini dikarenakan tema penelitian ini membutuhkan interaksi secara langsung dengan setting dan subyek penelitian. Hal ini dilakukan agar peneliti dapat memperoleh data yang natural. Penelitian berlokasi di Kantor Yufid TV, Jl. Kaliurang KM 8 - Jl. Damai, Gg. Sumberan 2 Sleman Yorgyakarta.

Penelitian ini menggunakan informan pangkal dan informan kunci. Penentuan kedua jenis informan tersebut, dilakukan dengan seleksi berdasarkan kriteria. Adapun kriteria informan pangkal adalah: pihak Yufid TV yang memahami secara umum tentang kegiatan di Yufid TV, baik direktur atau salah satu karyawan yang bisa memberikan petunjuk/pengetahuan umum kepada peneliti serta mampu memberikan rekomendasi kepada peneliti dalam pelacakan data lebih terinci.

Teknik pengumpulan data yang dilakukan meliputi observasi, wawancara mendalam, dan dokumentasi. Adapun untuk informan kunci, dalam wawancara adalah koordinator program dan karyawan yang bekerja pada bidang tersebut. Kriteria-kriteria informan kunci dalam penelitian ini adalah pertama, karyawan yang minimal 5 tahun telah berkecimpung di Yufid TV terutama dalam program Bincang Ringan Angkrinan. Kedua, karyawan yang bekerja kurang dari 5 tahun dengan rekomendasi karyawan kriteria pertama.

Adapun wawancara dilakukan dengan empat informan. Informan pertama adalah Zakky, yaitu admin Yufid yang mana dalam penelitian ini merupakan informan pangkal. Wawancara dilakukan secara online melalui telepon pada tanggal 5 Agustus 2020 sekitar pukul 14.21 WIB. Informan kedua, Joko Sujito yang merupakan pencetus munculnya program "Bincang Ringan Angkringan" sekaligus sebagai editor video Yufid. Wawancara dilakukan secara online melalui panggilan video whatsapp pada tanggal 6 Agustus 2020 sekitar pukul 11.02 WIB. Informan ketiga yaitu Tri Romadhona. Tri Romadhona adalah talent atau aktor yang berperan sebagai tokoh Mas Tri, selain itu Tri juga 
merupakan penulis naskah "Bincang Ringan Angkringan". Wawancara dilakukan secara langsung di kantor Yufid pada tanggal 9 Agustus sekitar pukul 9.30 WIB. Informan terakhir adalah Riza Sanad. Riza adalah DOP (Director Of Photography) sekaligus Sinematografer, juga menjadi aktor dari tokoh Mas Riza. Wawancara dilakukan secara online melalui panggilan video whatsapp pada tanggal 10 Agustus 13.32 WIB.

Dalam pengumpulan data, adapun peneliti juga menggunakan observasi dan dokumentasi. Dokumen yang dijadikan bahan dalam observasi adalah kegiatan di Yufid TV dan 10 video dari program Bincang Ringan Angkringan. Adapun 10 video tersebut adalah dengan judul 'Pilih Kiri atau Kanan?'; 'Haruskah Wudhu 2x?'; 'Dzikir Saat Jalan Naik dan Turun'; 'Siksa Kubur - Kencing Berujung Siksa Kubur'; 'Niat Puasa Ramadhan'; 'Uang Apa Beras?'; 'Kurban Itu?'; 'Mandi Keramas'; 'Sholat Atau Mandi Dulu'; dan 'Jangan Buang Sampah Sembarangan'.

Reduksi data dilakukan dengan mengkategorisasi data-data yang sesuai kemudian diambil, sedangkan yang tidak sesuai dengan tujuan penelitian maka dikesampingkan. Penarikan kesimpulan akan menggunakan sudut pandang dari tokoh ahli dalam strategi dakwah kultural.

\section{HASIL DAN PEMBAHASAN}

HASIL

Proses Produksi Program 'Bincang Ringan Angkringan'

Al-Bayanuni mendefinisikan strategi adalah "Sistem dan rencana yang teratur mengenai sesuatu" (1995). Berdasarkan wawancara yang penulis lakukan dengan informan, Program Bincang Ringan Angkringan pada awalnya dimulai dengan sekedar membuat karya coba-coba. Bermula dari usulan salah satu anggota tim kreatif Yufid. Dibuatlah video pendek yang bersetting di angkringan dengan tema besar Adab-adab makan dalam Islam, diambillah bab makan dengan tangan kanan, maka jadilah video tersebut dengan judul "Pilih Kanan Atau Kiri?” Setelah dirasa mendapatkan respon yang cukup bagus dari warganet, barulah video-video setelahnya mulai disetting dengan perencanaan yang matang.

Proses pembuatan video Bincang Ringan Angkringan dijelaskan oleh Tri, yang merupakan script writer dari program ini.

"Awalnya brainstorming dulu beberapa orang, ditentukan tema besarnya apa, setelah ketemu nanti saya yang buat scriptnya, skenario, penentuan angel kamera. Kemudian produksi shooting. Kemudian editing, biasanya sutradara sama editor, kemudian di akhir video diberikan VO untuk pembacaan hadits yang menjadi tema. setelah jadi kemudian memasuki proses QC, setelah di acc maka kemudian diupload." (Wawancara dengan Tri Romadhona - Penulis Naskah \& Aktor, 7 Agustus 2020: 09.30)

Dari petikan wawancara tersebut bisa diperoleh gambaran bagan sebagai berikut:

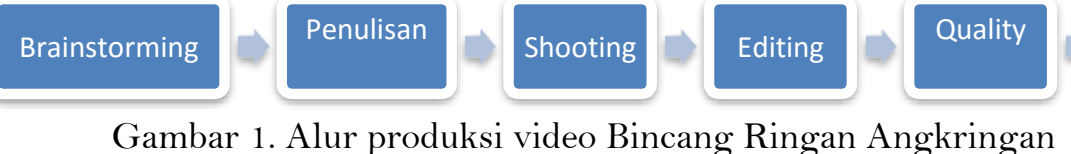

Alur produksi video "Bincang Ringan Angkringan" dimulai dari proses brainstorming, setelah itu dilanjut pada penulisan naskah. Kemudian masuk ke proses produksi lapangan yakni shooting. Dilanjutkan dengan proses editing video. Setelah selesai diedit, maka video tersebut melalui proses pengecekan atau quality control $(Q C)$ oleh pihak manajemen Yufid. Ketika sudah lolos QC maka video tersebut diunggah ke youtube. 


\section{Strategi Dakwah Sentimentil}

Strategi sentimentil (al-manhaj al-'athifi) adalah dakwah yang memfokuskan aspek hati dan menggerakkan perasaan dan emosi mitra dakwah (Al-Bayanuni, 1995). Al-Bayanuni juga menyebutkan 3 karakteristik dari strategi sentimentil yakni; 1) Gaya bahasa "mau'idzoh hasanah", 2) Menampakkan kelembutan dan kasih sayang terhadap mitra dakwah, 3) Memenuhi kebutuhan mitra dakwah.

Menurut Abdul Hamid al-Bilali bahwa al-mau'idzoh al-hasanah merupakan salah satu manhaj (metode) dalam dakwah untuk mengajak ke jalan Allah dengan memberi nasihat atau bimbingan dengan lemah lembut agar mereka mau berbuat baik (al-Bilali, 1989, p. 260).

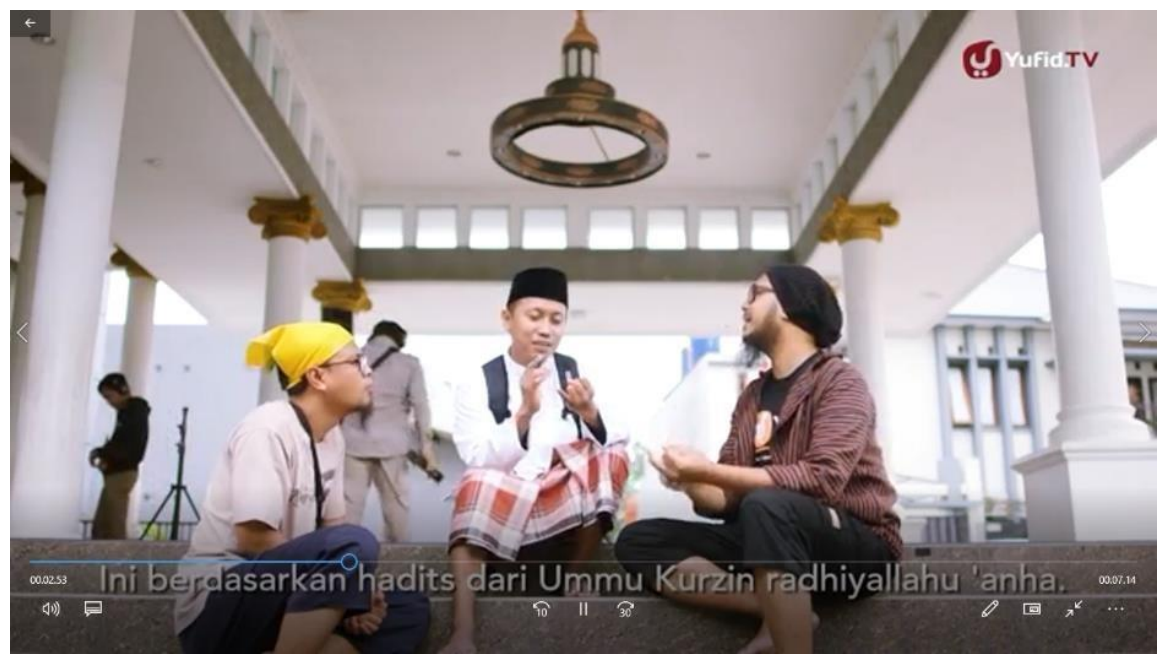

Gambar 1. Ustadz Ammi sedang menjelaskan masalah kurban kepada Tri dan Riza (sumber: Youtube Yufid TV)

Diantara bentuk mau'idzoh hasanah yang dijelaskan oleh al-Bayanuni adalah $d a^{\prime} i$ memuji atau mengkritik mitra dakwah, bisa dengan menyebutkan kebaikan dari mitra dakwah atau kesalahannya. Hal ini terdapat dalam beberapa video Bincang Ringan Angkringan. Salah satunya adalah video yang berjudul "Kurban Itu?". Dimana ada tokoh Mas Tri dan Mas Riza sedang kebingungan tentang hewan yang sah untuk bisa dijadikan sebagai hewan kurban. Kemudian Ustadz Ammi memberikan jawaban dari pertanyaan serta meluruskan kesalahan yang terjadi di masyarakat.

Demikian pula dalam beberapa video lainnya dalam program Bincang Ringan Angkringan, tokoh Ustadz Ammi memberikan mau'idzoh hasanah kepada Mas Tri dan Mas Riza yang berperan sebagai orang biasa untuk mewakili pemirsa.

Ciri menonjol kedua dari strategi sentimentil adalah menampakkan kelembutan dan kasih sayang terhadap mitra dakwah. Bentuknya bisa berupa ucapan yang baik, santun, dan bisa membekas di hati mitra dakwah. Pada pengamatan yang dilakukan oleh peneliti, ciri-ciri tersebut yakni ditampakkannya sikap kelembutan juga kasih sayang terhadap mitra dakwah tergambar dalam salah satu video angkringan yang berjudul "Sholat Atau Mandi Dulu".

Dalam video yang berjudul “Sholat Atau Mandi Dulu?” Ustadz Ami mengucapkan salam kemudian berbicara menggunakan bahasa jawa krama ketika bertemu dengan Mas Tri dan teman-temannya yang sedang mengalami masalah pada motor yang dikendarai. 


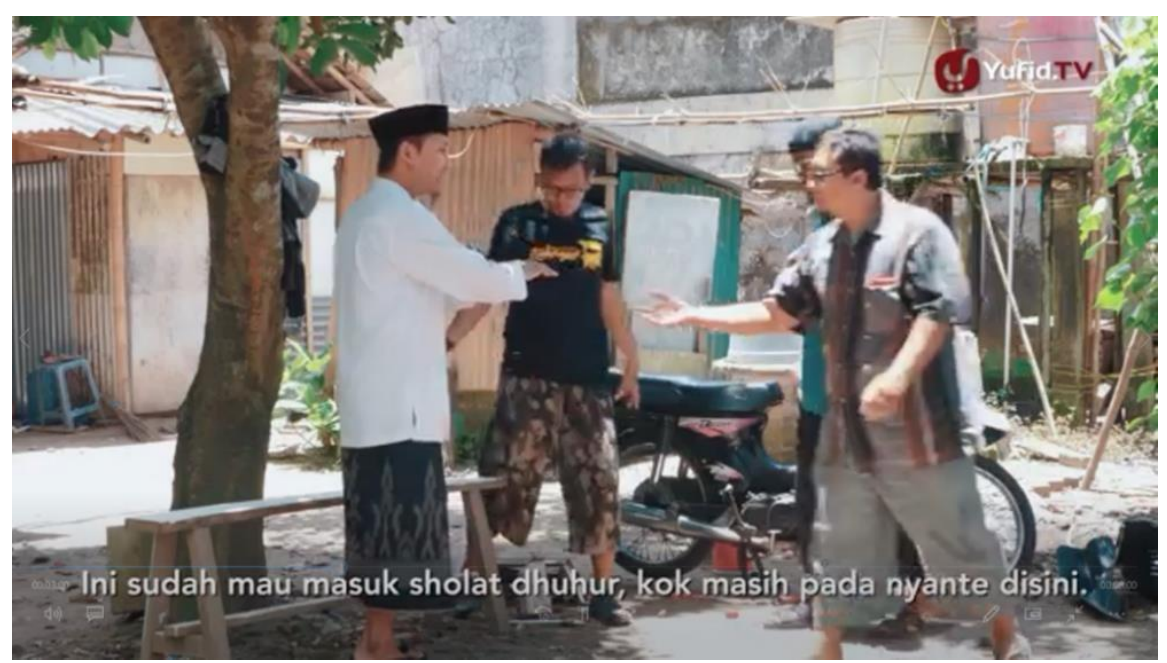

Gambar 2. Ustadz Ammi menyapa Tri dan kawan-kawan dalam episode "Sholat atau Mandi Dulu" (sumber Youtube Yufid TV)

Kebutuhan mitra dakwah yang masih awam, tentu berbeda dengan kalangan santri. Hal ini sebagaimana yang disampaikan oleh Zakky dalam wawancara penelitian ini.

"Yufid kan channel Islam jadi secara umum intinya kita bikin konten yang cocok untuk orang yang paling awam, bahkan mungkin baru masuk Islam bisa langsung paham terhadap konten yang disampaikan." (Wawancara dengan Zakky - Admin Yufid, 5 Agustus 2020: 14.21)

Berdasarkan kutipan wawancara diatas. Zakky memberikan penjelasan bahwa Yufid dalam program angkringan ini memang menargetkan konten untuk orang awam atau bahkan muallaf. Hal ini sesuai dengan karakteristik daripada strategi sentimentil itu sendiri untuk bisa memenuhi kebutuhan spiritual mitra dakwah.

Hal yang sama juga disampaikan oleh Joko Sujito ketika menjelaskan mengenai pangsa dakwah dari program ini.

"Kalau ide awal program ini memang dari saya, bagaimana caranya untuk mengemas penyampaian dakwah untuk orang awam dengan materi yang ringan." (Wawancara dengan Joko Sujito - Penggagas Program Angkringan rufid \& Editor, 6 Agustus 2020: 11.02).

\section{Strategi Dakwah Rasional}

Strategi rasional (al-manhaj al-'aqli) adalah dakwah dengan beberapa metode yang memfokuskan pada aspek akal pikiran. Strategi ini mendorong mitra dakwah untuk berpikir, merenungkan dan mengambil pelajaran. Al-Bayanuni menyebutkan bahwa strategi rasional memiliki 4 karakteristik, yakni; 1) Dialog Rasional, 2) Debat, diskusi, dan dialog, 3) Pemberian contoh-contoh disertai rinciannya baik yang explisit maupun implisit, 4) Kisah-kisah yang membuat seseorang berpikir dengan akalnya.

Strategi ini tidak begitu diterapkan oleh Yufid dalam program angkringan. Hal ini dikarenakan target pemirsa dari program angkringan adalah orang-orang awam yang rata-rata menyukai bahasa yang ringan. Sementara strategi rasional mengajak mitra dakwah untuk berpikir. Begitu pula sebagaimana wawancara penulis kepada Sujito bahwa tim Yufid TV pernah melakukan survei melalui grafik dari video Bincang Ringan Angkringan.

"Sesuai dengan survei kita bahwa orang-orang awam tidak senang digurui, ketika dengar kata ustadz seperti sudah anti duluan. Maka dari itu kita meminimalisir banget program angkringan dalam 
menampilkan ustadz. Sehingga orang awam merasa tidak digurui. Orang-orang awam lebih menerima hal yang menggambarkan keadaan mereka. Dengan contoh-contoh adab yang biasa mereka lupakan itu lebih mengena." (Wawancara dengan Joko Sujito - Penggagas Program Angkringan Yufid E Editor, 6 Agustus 2020: 11.02)

Hal tersebut dikuatkan juga oleh Tri. Bahwa tema-tema yang dipilih untuk Bincang Ringan Angkringan bukanlah tema yang bisa menimbulkan perdebatan.

"Dalam angkringan ini kami memilih temanya bukan tema-tema yang kontroversial, bukan tema-tema yang bisa banyak menimbulkan perdebatan, ini sudah dipikirkan sejak proses brainstorming." (Wawancara dengan Tri Romadhona - Penulis Naskah ङ Aktor, 7 Agustus 2020: 09.30)

Akan tetapi ada beberapa video dari Bincang Ringan Angkringan yang menerapkan strategi ini. Video yang mengajak pemirsa untuk berpikir ini biasanya dihadirkan tokoh Ustadz. Salah satunya yaitu pada video yang berjudul "Kurban Itu?", kemudian video yang membahas tentang riba. Mengenai hal ini Sujito memberikan penjelasan bahwa pemirsa yang awam tentang agama kurang begitu suka dengan adanya figur ustadz.

"Ada beberapa tema yang berat seperti riba. Dan dalam hal ini kita perlu mendatangkan ustadz untuk bisa menjelaskan. Dan tema ini merupakan percobaan. Dan ternyata banyak komentar yang belum bisa menerima materi yang disampaikan. Dan itu memang sengaja kita coba untuk memasukkan tema-tema berat itu untuk survey." (Wawancara dengan Joko Sujito - Penggagas Program Angkringan Yufid \& Editor, 6 Agustus 2020: 11.02)

Lebih lanjut Sujito menerangkan bahwa pemirsa kurang begitu suka dengan tokoh Ustadz, ia menjelaskan hal tersebut bisa dilihat berdasarkan traffic Youtube. Menurutnya, grafik menjadi turun setelah tokoh ustaz ditampilkan.

"Pernah kami coba melihat traffic, setelah masuk ke adegan ustadz ternyata grafiknya turun. Jadi dari situ kami simpulkan orang-orang awam tidak begitu suka dengan figure ustadz karena merasa digurui. Dan itu juga sudah disetujui oleh dewan Pembina." (Wawancara dengan Joko Sujito - Penggagas Program Angkringan Yufid Eं Editor, 6 Agustus 2020: 11.02)

Traffic yang dimaksud adalah grafik berupa curva yang menurun pada menit ketika tokoh ustadz mulai memberikan penjelasan tentang masalah yang sedang dibahas pada video tersebut. Munculnya kesamaan gejala pada setiap video yang menampilkan tokoh ustadz tersebut menjadikan kerabat kerja "Bincang Ringan Angkringan" mengurangi munculnya tokoh ustadz pada program ini, dan keputusan tersebut disetujui oleh dewan Pembina Yufid.

\section{Strategi Dakwah Indrawi}

Al-Bayanuni menyebutkan bahwa karakteritstik dari strategi indrawi adalah; 1) Menggambarkan sesuatu yang abstrak menjadi sesuatu yang dapat dirasakan atau diindera dengan jelas, 2) Metode praktik, Keteladanan dalam beramal untuk mengajarkan akhak dan adab, 4) Mengingkari kemungkaran dengan tangan, 5) Mendukung adanya kebenaran mu'jizat para nabi terdahulu, 6) Dakwah dengan metode pementasan drama.

Pertama, menggambarkan sesuatu yang abstrak menjadi sesuatu yang dapat dirasakan atau diindera dengan jelas. Sesuatu yang bersifat naratif akan tampak menjadi lebih jelas ketika diaplikasikan. Yang tadinya terasa abstrak karena baru sebatas tulisan ataupun suara, kemudian 
menjadi sesuatu yang lebih mudah difahami ketika hal tersebut divisualkan. Ini menjadi salah satu karakteristik strategi indrawi.

Diantara video Bincang Ringan Angkringan yang menunjukkan hal ini adalah yang berjudul "Dzikir Saat Jalan Naik dan Turun". Video ini memvisualkan bagaimana cara mempraktekkan doa yang dibaca ketika di dalam perjalanan, kemudian dalam perjalanan tersebut terdapat jalan naik ataupun jalan yang menurun. Doa tersebut adalah takbir ketika jalanan menanjak dan tasbih ketika jalanan menurun sebagaimana yang terdapat dalam hadits, "Nabi shallallahu 'alaihi wasallam dan pasukannya apabila melewati jalanan perbukitan yang naik, mereka bertakbir, dan apabila mereka turun, mereka bertasbih. (HR. Abu Daud 2601 dan dishahihkan al-Albani).

Video ini merupakan episode pertama dari beberapa video serial perjalanan Mas Tri dengan Mas Riza yang akan berangkat camping di hutan. Riza mengajak Tri untuk berdzikir membaca takbir ketika jalanan menanjak dan membaca tasbih ketika jalanan menurun.

Metode praktik Strategi ini banyak diterapkan oleh Yufid dalam program Bincang Ringan Angkringan. Dalam penggambaran tokoh utama sendiri sengaja dibuat agar bisa mewakili masyarakat yang awam dalam masalah agama.

"Jadi ada di tiap episode ada yang berakting sebagai orang awam, ataupun mewakili orang awam, dan ada tokoh yang mewakili orang yang tahu. Disitu masyarakat diwakili tokoh awam tersebut dan ia mempraktekkan secara langsung sehingga mudah ditiru pemirsa." (Wawancara dengan Tri RomadhonaPenulis Naskah E゚ Aktor, 7 Agustus 2020: 09.30).

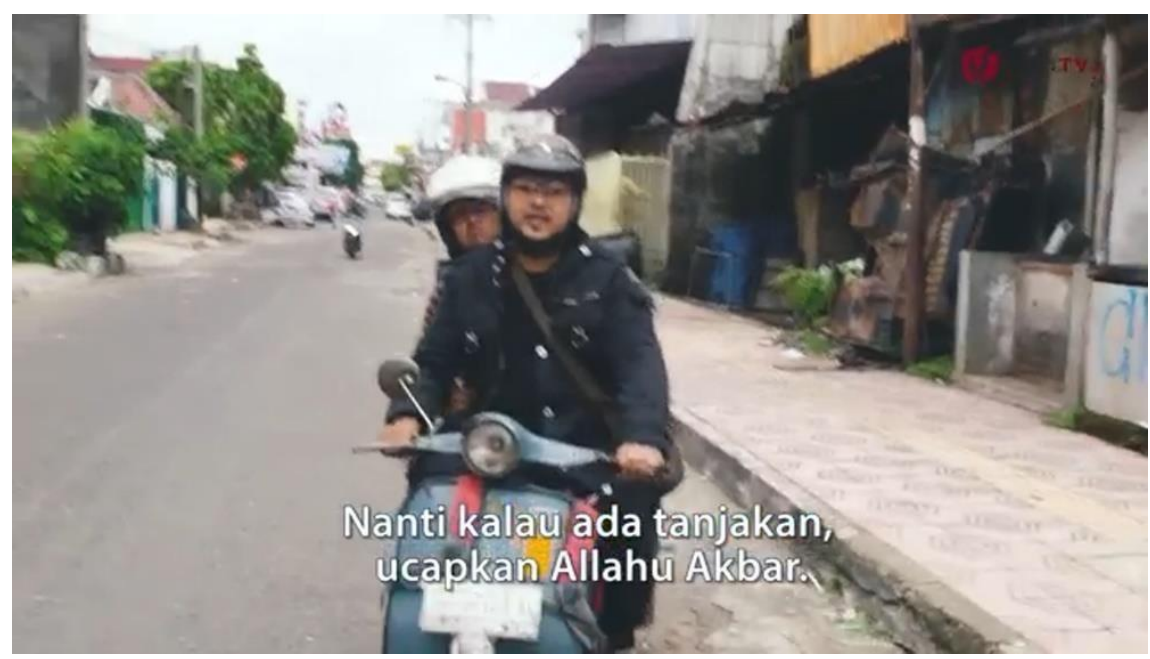

Gambar 3. Riza mengajak Tri untuk berdzikir ketika melalui tanjakan dan tasbih ketika jalan menurun (sumber: youtube Yufid TV)

Dalam kutipan di atas Tri menjelaskan bahwa penggambaran tokoh utama digambarkan sebagai orang awam yang kurang memiliki ilmu agama. Penggambaran tersebut dilengkapi dengan adanya tokoh ustadz yang mengetahui ilmu agama, atau kawan sebaya yang pernah belajar agama, atau sekedar pernah mengetahui ilmunya kemudian disampaikan.

Salah satu contohnya adalah dalam video yang berjudul "Pilih Kanan atau Kiri". Video ini mengkisahkan Mas Riza yang sedang makan di angkringan, kemudian datang Mas Tri masuk ke tempat angkringan kemudian duduk membersamai Mas Riza. Melihat Tri seperti sedang kesulitan finansial maka Riza mentraktir Tri untuk ikut makan bersama-sama. Ketika Tri sedang makan gorengan lalu mengambil cabai, dipegangnya gorengan dengan tangan kanan dan cabai di tangan kirinya. Melihat Tri ingin memakan cabai dengan tangan kirinya sontak Riza langsung menghalangi 
Tri dan menjelaskan bahwa makan itu harus memakai tangan kanan. Kemudian Riza mengajari Tri bagaimana caranya memakan gorengan dan cabai dengan tangan kanan.

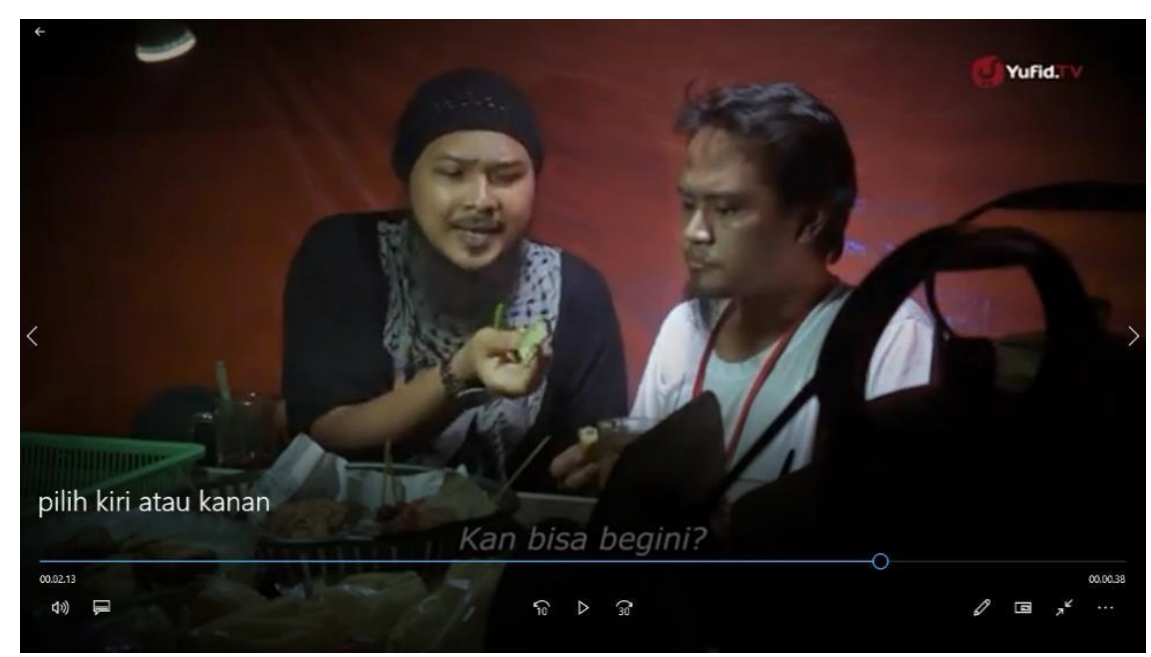

Gambar 4. Riza sedang mengajari Tri cara makan cabai dengan tangan kanan sewaktu makan gorengan (sumber: Youtube Yufid TV)

Dalam strategi dakwah indrawi, dijelaskan mengenai keteladanan dalam beramal untuk mengajarkan akhlak dan adab. Selain itu strategi dakwah ini diharapkan mampu memberikan teladan atau contoh secara nyata sebuah amalan. Strategi dakwah indrawi, di dalamnya juga memberikan teladan untuk dalam berakhlak dan beradab. Salah satu video Bincang Ringan Angkringan yang tampak menunjukkan keteladanan akhlak dan adab adalah video yang berjudul "Siksa Kubur: Kencing Berujung Siksa Kubur”. Diantara akhlak yang disampaikan secara eksplisit adalah tidak mengganggu orang lain dengan kencing sembarangan. Karena bau air kencing yang tidak sedap akan tercium ketika seseorang kencing sembarangan.

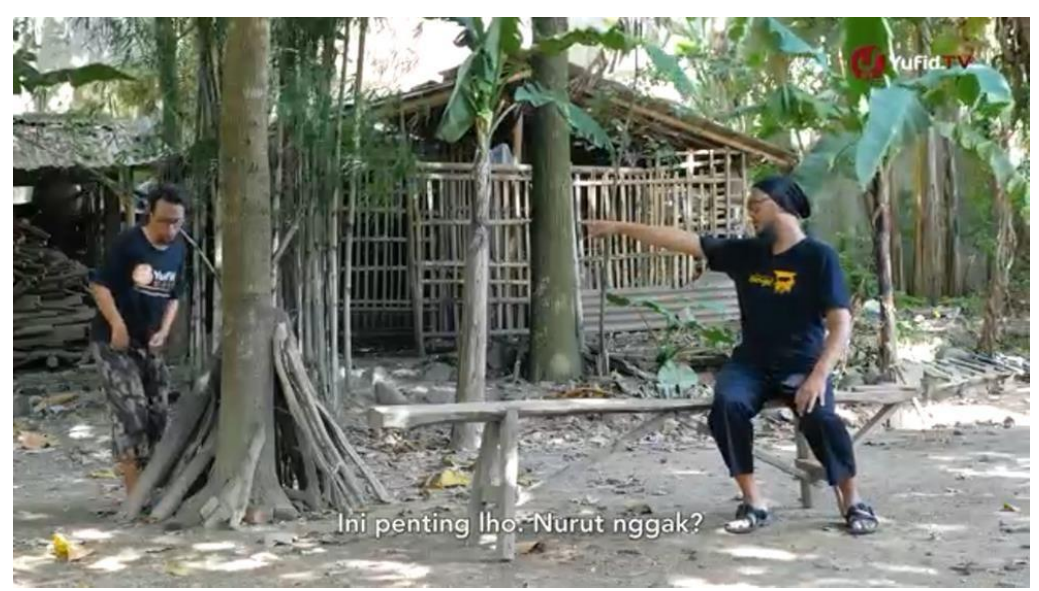

Gambar 5. Riza sedang mencegah Tri untuk tidak kencing sembarangan (sumber: Youtube Yufid TV)

Adapun dari sisi adab buang hajat, ketika tidak didapati toilet atau tempat khusus untuk buang hajat, maka Islam mengajarkan untuk kita buang hajat di tempat yang; tidak terlihat oleh manusia, bukan di jalan yang biasa dilalui, atau tempat yang biasa disinggahi manusia untuk berteduh, bukan pula kencing di air yang tidak mengalir (Tuasikal, 2020).

Dalam Islam penerapan tertinggi nahi munkar ataupun pengingkaran terhadap suatu kemungkaran adalah dicegah kemungkaran tersebut dengan tangan, tingkatan selanjutnya adalah pengingkaran 
dengan lisan, baru yang terendahnya adalah mengingkari dengan hati. Hal tersebut disesuaikan dengan kondisi masing-masing orang. Dalam point ini tentu saja pihak Yufid sebagai $d a^{\prime} i$ tidak secara langsung melakukan pengingkaran dengan tangan terhadap pemirsa ketika ada yang melakukan kemungkaran. Berbeda halnya dengan seorang da'i yang terjun di lapangan, melihat teman atau mad'unya hendak berbuat kemungkaran hal tersebut bisa ia cegah secara langsung. Namun ada contoh pengingkaran kemungkaran dengan tangan dalam video Bincang Ringan Angkringan, salah satunya adalah video yang berjudul "Jangan Buang Sampah Sembarangan". Dalam video tersebut diperlihatkan Fikri mencegah Tri untuk tidak membuang sampah sembarangan di sungai.

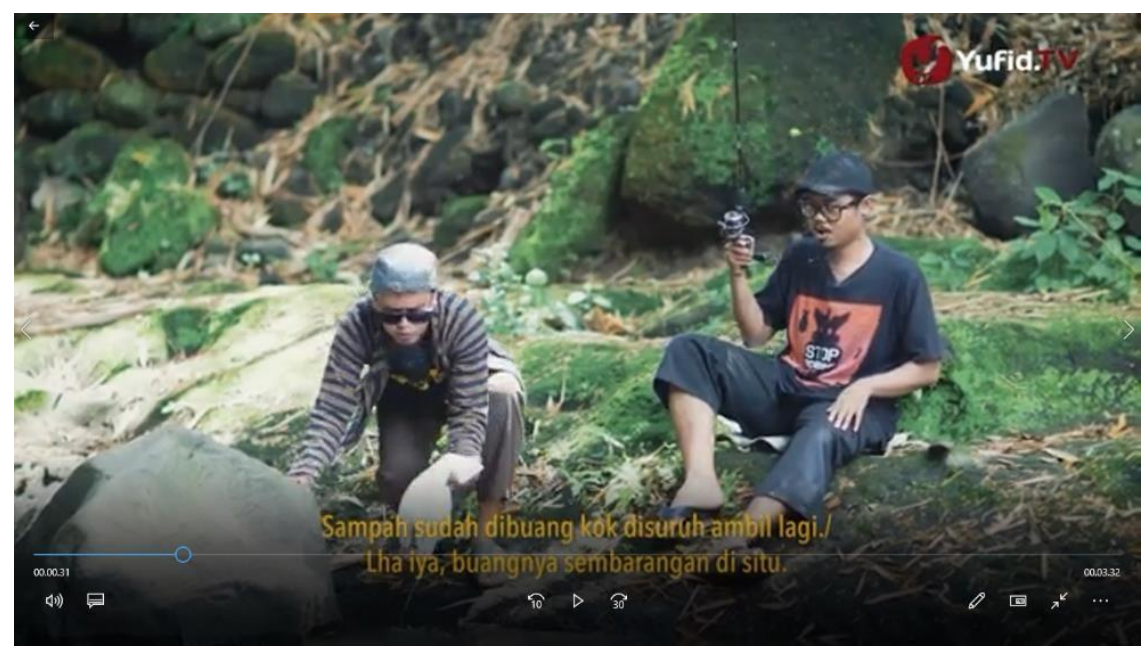

Gambar 6. Fikri sedang mencegah Tri untuk tidak membuang sampah di sungai (sumber: youtube Yufid TV)

Dalam video program 'Bincang Ringan Angkringan' salah satu strategi rasional menjelaskan tentang mendukung adanya kebenaran mu'jizat para nabi terdahulu. Di antara mu'jizat Nabi adalah Allah memberitahukan sebagian perkara ghaib atau yang tidak terlihat oleh manusia biasa kepada Nabi. Salah satunya adalah mengetahui bagaimana cara makan dan cara tidurnya setan. Hal tersebut tidak bisa kita indera. Akan tetapi Nabi Muhammad shallahu'alaihi wasallam pernah menjelaskan bahwa setan makan dengan tangan kiri, demikian pula setan tidur dengan cara tengkurap.

Salah satu video Bincang Ringan Angkringan yang menunjukkan dukungan terhadap mukjizat nabi ini adalah yang berjudul "Tidurnya Setan". Diceritakan bahwa Riza dengan Tri sedang camping di hutan pinus. Kemudian Tri masuk tenda untuk tidur. Ketika Riza datang dan hendak masuk ke dalam tenda ia melihat Tri sedang tidur dalam keadaan tengkurap. Kemudian Riza menjelaskan bahwa tidur dengan cara tengkurap itu adalah tidurnya setan, berdasarkan hadits Nabi. Kemudian Riza mengajarkan kepada Tri bagaimana posisi tidur yang dicontohkan oleh Nabi Muhammad shallallahu'alaihi wasallam.

\section{PEMBAHASAN}

Deddy Mulayana menjelaskan bahwa dewasa ini dakwah harus disesuaikan dengan kondisi masyarakat. Hal ini menggambarkan bahwa era perbedaan kebutuhan pesan-pesan dakwah berdasarkan daya serap mad'u. Jika mubaligh memiliki kepekaan rasa akan kebutuhan materi dakwah pada mad'u dalam menyebarkan pesan-pesan dakwah melalui penataan kata, kalimat yang berat, dan berbekas dalam proses dakwah (Mulyana, 2005).

Di antara aspek-aspek yang perlu diperhatikan dalam kondisi mitra dakwah adalah tabiat, lingkungan, budaya, agama, dan pendidikan mad'u. (Syarifudin, 2012). Hal tersebut menekankan pentingnya membuat materi dakwah yang sesuai dengan tingkat kecerdasan dan nalar mad'u. Dalam 
hal ini, mubaligh harus mempersiapkan materi dakwah yang sesuai dengan kebutuhan mad'u, mengemasnya dalam bahasa yang mudah dimengerti, dan menggunakan media dakwah sebagai penunjang mubalig yang sesuai kebutuhan level dakwah dan mad'u.

Pemanfaatan teknologi dakwah sebenarnya merupakan sebuah pemenuhan kebutuhan spiritual masyarakat Indonesia yang selalu mengalami perkembangan akan eksistensinya sebagai konskuensi modernisasi zaman (Ahmad, 2016). Tentu saja penggunaan media sosial seperti Youtube untuk dakwah merupakan salah satu usaha Yufid dalam memenuhi kebutuhan spiritual mitra dakwah di era milenial.

Strategi dakwah indrawi (al-manhaj al-hissi) adalah kata lain dari strategi eksperimen atau strategi ilmiah. Strategi ini didefinisikan sebagai sistem dakwah atau kumpulan metode dakwah yang berorientasi pada pancaindra dan berpegang teguh pada hasil penelitian dan percobaan. Di antara metode ini dihimpun oleh strategi yaitu praktik keagamaan, keteladanan, dan pentas drama (Nizar, 2018).

Strategi dakwah indrawi juga dijalankan dengan metode pementasan drama. Dakwah dengan model drama merupakan dakwah yang memerlukan pemeran. Dalam hal ini Yufid menjadikan salah satu bentuk dakwah dengan drama adalah program Bincang Ringan Angkringan ini. Oleh karena itu secara langsung kriteria ke enam dari strategi Indrawi ini secara otomatis masuk dalam video "Bincang Ringan Angkringan".

\section{KESIMPULAN}

Mengelola sebuah media dakwah oleh penda'i dengan terstuktur dan baik, kini menjadi hal yang wajib. Saat kualitas banyak program non-dakwah lain berjalan dengan baik, maka, untuk menyebarkan islam, seyogiannya juga menjadi kewajiban untuk ditampilkan dengan baik pula. Banyak strategi dakwah yang dapat diaplikasikan, tentu saja, hal ini harus disesuaikan dengan target dakwah/mad'u/mitra dakwah dan media yang digunakannya.

Dalam mengelola social media youtube oleh Yufid TV, peneliti menemukan bahwa Yufid dalam program ‘Bincang Ringan Angkringan’ ini dominan menggunakan strategi dakwah indrawi, kemudian strategi sentimentil, dan sangat jarang menggunakan strategi rasional. Ini berdasarkan pengamatan peneliti dan keterangan informan yang menjelaskan bahwa program ini ditujukan untuk orang awam yang secara umum kurang suka dengan tokoh ustadz karena merasa digurui. Sehingga dalam penerapannya strategi rasional jarang digunakan kecuali dalam sebagian kecil video saja. Dalam penerapannya lebih cenderung menerapkan strategi indrawi juga strategi rasional. Tentu saja hal ini tidak terlepas dari target dakwah dan chanel youtube sebagai media yang digunakannya.

\section{REFERENSI}

Agu, S. U., Okwo, I. M., Ugwunta, O. D., \& Idike, A. (2014). Fiscal Policy and Economic Growth in Nigeria: Emphasis on Various Components of Public Expenditure. Singaporean Journal of Business Economics, and Management Studies, 2(12), 24-37. doi: https://doi.org/10.12816/0006800

Al-Bayanuni, A. F. (1995). Al-Madhkal Ila 'Ilmid Da'wah. Beirut: Muassasah Risalah

Aron, L., Botella, M., \& Lubart, T. (2019). Culinary arts: Talent and their development. In R. F. Subotnik, P. Olszewski-Kubilius, \& F. C. Worrell (Eds.), The psychology of high performance: Developing human potential into domain-specific talent (pp. 345-359). American Psychological Association. https://doi.org/10.1037/0000120-016

Bachtiar, M. (2013). Dakwah Kolaboratif: Model Alternatif Komunikasi Islam Kontemporer. Jurnal Komunikasi Islam.

Creswell, J.W. (2004). Fourth edition research design: qualitative, quantitative, and mixed methods approaches. London: SAGE Publications, Inc.

Johnson, S. (2013). Style strategies (Master's thesis). UCOL, Whanganui School of Design, Whanganui, New Zealand.

Kristol, I. (1983). Reflection of a Neoconservative: Looking Back, Looking Ahead. New York: Free 
Nizar, M. (2018). Strategi Dakwah Al-Bayanuni (Analisis Strategi Muhammad Abu Fatah AlBayanuni dalam Kitab Al-Madkhal Ila 'Ilmi Dakwah). Islamic Communication Jurnal, 74-87.

Mann, D. L. (2010). Vision and expertise for interceptive actions in sport (Doctoral dissertation, The University of New South Wales, Sydney, Australia). Retrieved from http://handle.unsw.edu.au/1959.4/44704

McKinney, C., \& Smith, N. (2005). Te Tiriti o Waitangi or The Treaty of Waitangi: What is the difference? In D. Wepa (Ed.), Cultural safety in Aotearoa New Zealand (pp. 39-57). Auckland, New Zealand: Pearson Education New Zealand.

Sapolsky, R. M. (2017). Behave: The biology of humans at our best and worst. Penguin Books.

Sulthon, M., Syukur, H. A., \& Abdusshomad, M. A. (2003). Menjawab tantangan zaman: desain ilmu dakwah: kajian ontologis, epistemologis dan aksiologis. Pustaka Pelajar bekerja sama dengan Walisongo Pers. 